\title{
Prevalence of HBV and HBV vaccination coverage in health care workers of tertiary hospitals of Peshawar, Pakistan
}

\author{
Sobia Attaullah ${ }^{1 \dagger}$, Sanaullah Khann ${ }^{2 \dagger}$, Naseemullah ${ }^{3}$, Sultan Ayaz ${ }^{2}$, Shahid Niaz Khan², ljaz Ali $^{4}$, Naseruddin Hoti ${ }^{5}$ \\ and Sami Siraj ${ }^{6 *}$
}

\begin{abstract}
Background: Hepatitis B Virus (HBV) may progress to serious consequences and increase dramatically beyond endemic dimensions that transmits to or from health care workers ( $\mathrm{HCWs}$ ) during routine investigation in their work places. Basic aim of this study was to canvass the safety of HCWs and determine the prevalence of HBV and its possible association with occupational and non-occupational risk factors. Hepatitis B vaccination coverage level and main barriers to vaccination were also taken in account.

Results: A total of 824 health care workers were randomly selected from three major hospitals of Peshawar, Khyber Pakhtunkhwa. Blood samples were analyzed in Department of Zoology, Kohat University of Science and Technology Kohat, and relevant information was obtained by means of preset questionnaire. HCWs in the studied hospitals showed $2.18 \%$ prevalence of positive HBV. Nurses and technicians were more prone to occupational exposure and to HBV infection. There was significant difference between vaccinated and non-vaccinated HCWs as well as between the doctors and all other categories. Barriers to complete vaccination, in spite of good knowledge of subjects in this regard were work pressure (39.8\%), negligence (38.8\%) un-affordability (20.9\%), and unavailability (0.5\%).
\end{abstract}

Conclusions: Special preventive measures (universal precaution and vaccination), which are fundamental way to protect HCW against HBV infection should be adopted.

\section{Background}

Among the blood borne pathogens, hepatitis B virus (HBV) has gained the status of global public health threat by being the $10^{\text {th }}$ major deaths causing disease. HBV infects more than 2 billion peoples worldwide, of which over 350 million peoples are chronic carrier [1]. Currently $\mathrm{HBV}$ is the leading issue of concern in society and medicine particularly in our under-resourced health care system which lacks the safety measures necessary to avert the risks of infection [2,3]. Different country wide hospital based and population based HBV surveys (individual researchers) estimated a prevalence rate of $2-7 \%$, which places Pakistan in intermediate HBV prevalence zone.

\footnotetext{
* Correspondence: samisiraj.ibms@kmu.edu.pk

+ Contributed equally

${ }^{6}$ Institute of Basic Medical Sciences, Khyber Medical University Peshawar Pakistan

Full list of author information is available at the end of the article
}

During the past two decades this risk has become even more significant as the prevalence of HBV has increased significantly [4], and risk of contracting hepatitis B by HCWs is four fold higher as compared to general adult population $[1,5,6]$.

Worldwide annual proportion of HCWs exposed to HBV infection were about $5.9 \%[1,5]$. In developing countries, $40-60 \%$ of HBV infection in HCWs was attributed to professional hazard while in developed countries the attributed fraction was less than $10 \%$ due to vaccination coverage [1]. Being the instruments of healthcare system, their interaction with patients is likely to pose unavoidable safety risks for the HCW's [5-7]. The chances of contracting HBV after an HBV-contaminated accidental needlestick average one in 20 while chance of contracting HCV after an accidental needlestick is 3.5 in 100 [4]. In addition to occupational hazards, evidences suggested that certain other unidentified community risk factors put HCWs at risk of

\section{() Biomed Central}


acquiring HBV, as the general population. There is a complex multiplicity of risks factors and it is difficult to tease out the biggest contributors to infection in HCWs $[8,9]$.

Hepatitis B is a vaccine preventable disease, though its implementation is still insufficient and a sizeable proportion of HCWs never get vaccinated. The risk of HBV infection in an unvaccinated person from a single HBVinfected needle stick injury ranges from 6-30\% [5]. Considering the importance of health care personnel and lack of any significant report in HCWs from the region of Peshawar, this study was designed to investigate the prevalence of HBV in different occupational groups of HCWs, predominant occupational and non-occupational modes of transmission, $\mathrm{HBV}$ vaccination coverage level and main barriers to vaccination.

\section{Methods}

\section{Study location}

This study was carried out at three large and tertiary hospitals of Peshawar, Khyber Pakhtunkhwa, namely Khyber Teaching Hospital, Lady Reading Hospital and Hayatabad Medical Complex Hospital, which provides services to the general population all over the province.

\section{Study sample}

The study undertook randomly selected $824 \mathrm{HCWs}$, working in different departments of the hospitals.

\section{Inclusion criteria}

HCWs with more than 6 months of job experience were included in this study.

\section{Instrument}

The information collection from HCWs was done via interview and through questionnaire. Data set included demographic parameters (gender, marital status, age, duration of employment, education, occupation and working department), history of frequency and nature of activities involved in occupational exposures, history of non-occupational risk factors (blood transfusion, hospitalization, surgery, dental treatment and intravenous drug use), history of HBV vaccination coverage status and time since vaccination, and barriers against vaccination status.

\section{Laboratory Technique}

Blood samples were collected from the population under investigation and tested in Molecular Parasitology and Virology Laboratory, Department of Zoology, Kohat University of Science and Technology (KUST) Kohat, for HBs Ag by immunochromatographic test (ICT). HBV DNA was isolated with GF-1 nucleic acid isolation Kit (Vivantus, USA), S gene of HBV was amplified with nested primers by PCR and amplified DNA was subjected to electrophoresis. The study was conducted after receiving ethical approval from medical superintendents of the respective hospital.

Participated HCWs were grouped into five categories on the basis of their jobs into medical staff including surgeons, physicians and dentists, nursing and midwifery staff, specialized technicians including X-rays, anesthesia and laboratory staff, assistant and general servicing staff including radiology, operational services, attendants, cleaning, laundry, blood bank, pharmacists, dispensers and administrative staff.

\section{Statistical analysis}

Categorical variables were shown in percentages. Chisquare test or Fishers' Exact Test were used to evaluate the association between seropositivity for HBV and categorical variables. A $p$ value less than 0.05 was set as significant level.

\section{Results}

Among the selected 824 subjects, $59.8 \%$ were male and $40.2 \%$ were female, $82.2 \%$ were married and $17.8 \%$ were unmarried, age ranged from $20-59$ years $(33.8 \pm 8.2$ years) and duration of employment from $>6$ months to 29 years (14.4 \pm 3.21 years). Of the total, $100 \mathrm{HCWs}$ had history of dental treatment, 98 had history of hospitalization, 31 had surgery in the past, 24 had been transfused and only one was intravenous drug user.

18 (2.18\%) HCWs were found positive for HBV while $\mathrm{HBV}$ and HCV mixed infection was not detected in any HCW. Characteristics and distribution (\%) of HBV positive and HBV negative are summarized in Table 1. Frequency of $\mathrm{HBV}$-infection in nurses was $44.4 \%, 33.4 \%$ in technicians, $22.3 \%$ in assistant staff while no doctor and administrative staff was found positive. Significant association $(P=0.328)$ between HBV prevalence and five occupational categories were present (Figure 1).

\section{Table 1 HCWs and HBV positivity}

\begin{tabular}{cccc}
\hline Variables & $\begin{array}{c}\text { HBV Negative N } \\
(\mathbf{\%})\end{array}$ & $\begin{array}{c}\text { HBV Positive N } \\
(\mathbf{\%})\end{array}$ & Total \\
\hline Male & $483(59.9)$ & $10(55.55)$ & 493 \\
\hline Female & $323(40.1)$ & $8(44.44)$ & 331 \\
\hline Married & $665(82.5)$ & $12(66.66)$ & 667 \\
\hline Unmarried & $141(17.4)$ & $6(33.33)$ & 147 \\
\hline Graduate & $554(68.7)$ & $1(5.55)$ & 555 \\
\hline Undergraduate & $252(31.3)$ & $17(94.4)$ & 269 \\
\hline H/O dental treatment & $20(2.48)$ & $4(22.22)$ & 24 \\
\hline H/O surgery & $94(11.66)$ & $6(33.33)$ & 100 \\
\hline H/O hospitalization & $27(3.35)$ & $4(22.22)$ & 31 \\
\hline H/O of intravenous drug & $91(11.2)$ & $7(38.9)$ & 98 \\
\hline use & $1(0.12)$ & $0(0)$ & 1 \\
\hline
\end{tabular}

$\mathrm{H} / \mathrm{O}=$ History of. 


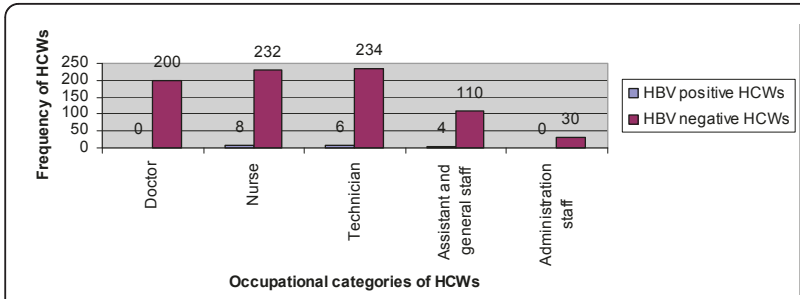

Figure 1 Distribution of HBV positive and HBV negative HCWs according to occupational categories.

As for personal data, neither gender $(P=1.000)$, nor marital status $(P=0.8575)$ were found responsible for any statistically significant differences in between HBV negative and HBV positive HCWs. However, a strong correlation was found with age $(P=0.0896)$, employment duration $(P=0.0001)$, dental treatment $(P=$ $0.0155)$, hospitalization $(P=0.0013)$, surgery $(P=$ $0.0004)$ and blood transfusion $(P=0.0001)$. All HCWs were aware of the importance of screening, but overall $24.5 \% \mathrm{HCW}$ sere aware of their viral status and only four (22.3\%) were aware of their seropositivity.

Overall, $572 \mathrm{HCW}$ sere involved in a total of 729 occupational exposures during the past one year period service. Percentage breakdown was $47.3 \%$ in nurses, $31.3 \%$ in technicians, $13.1 \%$ in doctors and $8.2 \%$ in assistant staff. Regarding the activity involved in occupational exposure, drawing blood was the main contributor (i.e. $33.6 \%$ ), followed by recapping of syringes (17\%), disposal of used needles (13.3\%), insertion of drip (12.6\%), trash collection $(9.7 \%)$, surgical procedure $(4.3 \%)$, collision with sharp objects $(4.1 \%)$, fluid splash $(3.0 \%)$, cleaning instruments (1.8\%) and others (0.5\%) (Table 2).

In this study, 605 (73.42\%) HCWs had completed their vaccination regimen. Of which $83(13.7 \%)$ had been vaccinated before entering the hospital, while 522 (86.3\%) received their vaccination after starting their job at the hospital. Regarding the vaccination status, highest coverage was found among doctors, followed by administrative staff, general and assistant staff, technicians and nurses. A significant difference in vaccine coverage in vaccination coverage was found between the doctors and all other categories $(P=0.0001)$ (Table 3$)$.

The most commonly cited reasons for no vaccination in $\mathrm{HCWs}$ found were unaffordability/ high costs (39.8\%), work pressure (38.8\%), negligence $(20.9 \%)$ and unavailability $(0.5 \%)$. Statistical analysis showed significant association between vaccinated verses non vaccinated coverage $(P=0.0005)$ and barriers to complete vaccination $(P=0.0001)$ (Figure 2$)$.

\section{Discussion}

Although the seroprevalence rate of $\mathrm{HBV}$ is on the rise in patient's population attending hospitals, screening is not routinely performed in most parts of country because of lack of public awareness, inadequate funding for health care setting and high cost of tests which poses a great threat to the safety of the healthcare workers [10]. The $2.18 \%$ prevalence in this study demonstrated that HCWs were at low increased risk for HBV infection when compared with the various previous studies conducted in Pakistan [8-12], except the recent study (0.5\%) [2]. The prevalence of $\mathrm{HBV}$ varies from place to place, may be due to difference in magnitude of HBV infection in patients, implementation of universal precautions and methodological strategies (employment duration, sample size etc).

In this study age and employment duration strongly correlated with HBV prevalence. One reason may be because seasoned staff member dealt with patients in an inadequately equipped set-up, which predisposed them to these risks even more. In addition to that, there was lack of awareness of personal prophylaxis and probably no or little vaccination option available to them. This logic is also proposed in other literatures [3,7,13-15]. Most of the HBVinfected HCW's in the present study had undergraduate level education. This fact alone is enough to put a rigorous emphasis on their proper education which also is most likely to serve as an effective tool in controlling the

Table 2 Analysis of risk factors of occupational exposure in HCWs

\begin{tabular}{|c|c|c|c|c|c|c|}
\hline Activities involved in exposure & Doctor $\mathrm{N}=72$ & Nurse $\mathrm{N}=238$ & Technician N = 209 & Assist. \& general staff $N=53$ & \multicolumn{2}{|c|}{ Total\% } \\
\hline Taking blood & 42 & 152 & 32 & 19 & 245 & 33.6 \\
\hline Recapping & 6 & 50 & 49 & 19 & 124 & 17 \\
\hline Disposal of syringes & 12 & 48 & 35 & 2 & 97 & 13.3 \\
\hline Insertion of drip & 3 & 47 & 40 & 2 & 92 & 12.6 \\
\hline Trash collection & 1 & 23 & 35 & 12 & 71 & 9.7 \\
\hline Surgical instrument & 18 & 9 & 4 & 0 & 31 & 4.3 \\
\hline Collection with sharp instrument & 2 & 7 & 19 & 2 & 30 & 4.1 \\
\hline Fluid splash & 12 & 7 & 2 & 1 & 12 & 3 \\
\hline Cleaning of instrument & 0 & 1 & 9 & 3 & 13 & 1.8 \\
\hline Others & 0 & 1 & 3 & 0 & 4 & 0.5 \\
\hline
\end{tabular}


Table 3 HCWs (\%) and their HBV vaccination status

\begin{tabular}{lcccccc}
\hline Vaccination status & Doctor & Nurse & Technician & Assist. \& general staff & Admin. staff & Total \\
\hline Complete & 85 & 65.4 & 70 & 75.6 & 20 & 73.4 \\
\hline Incomplete & 14.5 & 30.5 & 28.4 & 21.8 & 20 & 24.4 \\
\hline Continued & 0.5 & 4.1 & 1.6 & 2.6 & 0 & 2.2 \\
\hline
\end{tabular}

professional injuries $[15,16]$. Nurses and technicians were at high risk of $\mathrm{HBV}$ infection as they interact first-hand with the patients $[1,5,12,17,18]$. Prevalence of $\mathrm{HBV}$ might associate with their low socioeconomic status as it is the disease of poverty [3]. Similar to Sarwar and colleagues [9] none of doctor was found positive, but not in accordance to the other studies that among HCWs, surgeons/doctors have the highest risk of HBV infection from their patients $[11,19]$.

Current study showed that excessive risk of exposures among the HCW as a whole as well as among different occupations Nurses had the highest predisposition to occupational accidents, also reported by others $[4,6,18,20,21]$. Laboratory workers and anesthesia technicians comprised another major portion of occupational injuries, also analysed by the others $[4,7,12]$. In the current study the percentage of reported incidents in doctors was lower than other studies $[4,15,22]$. The absolute recording of professional injuries was frequent in nurses but percentage was actually greater in the physicians as this group was found more inclined to self assesses and not report such injuries [22]. The incidence of occupational exposure is common feature of studies across the world [22]. Factors associated with an increased risk of occupational exposure can differ from place to place depending on the standard of facilities [23-25]. Poor economic situation doesn't allow facility and personnel to achieve proper level of sophistication and therein lies the problem [26,27].

Assessment of HBV vaccination coverage in health care setting is needed to evaluate the proportion susceptible to HBV infection [1]. This study demonstrated that vaccination program was successful when compared with previous studies from diverse regions of Pakistan ranging from $37.2 \%$ to $66.3 \%[2,9,12,19,28-30]$ as well as

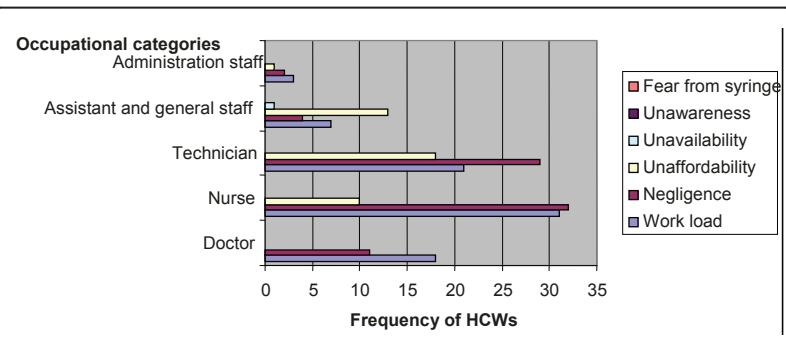

Figure 2 Analysis of risk factors against HBV vaccination coverage in HCWs. from other countries and regions such as Africa [1], Nepal [30], Japan, India, North Sydney, South London, Sweden and Egypt [31] but not satisfactory when compared with Australia, New Zealand [1], Iran and UK [30]. In recent study high $(81.8 \%)$ vaccination status was recorded from Karachi [32] but still universal coverage is not achieved despite the availability of vaccine since 2002 [4]. Most of the western countries recommend the need for immunization against $\mathrm{HBV}$ in the start of career in healthcare setting [1] but no such policy is employed in Pakistan, either in letter or in spirit.

It is a matter of fact that the risk factors against the vaccination coverage would vary among different occupations and among different regions of country [33,34]. Collection of the data of the risk factors against the vaccination provides valuable information for identification and evaluation. By eliminating these factors and providing necessary facilities, $100 \%$ vaccination coverage is well within the realm of possibility [31]. We believe our study was able to shed light on major hurdles to vaccine coverage, including work pressure, negligence and high cost of the vaccine. We also hope that our study can be used as a precedent to develop important guidelines which, if properly implemented, will be able to curb the one of the root causes of spread of Hepatitis B.

\section{Author details}

${ }^{1}$ Department of Zoology, Islamia College Peshawar (A Public Sector University) Khyber Pakhtunkhwa, Pakistan. ²Department of Zoology, Kohat University of Science and Technology Kohat, Pakistan. ${ }^{3}$ Lady Reading Hospital Peshawar, Khyber Pakhtunkhwa, Pakistan. ${ }^{4}$ Institute of Biotechnology and Genetic Engineering, KP University of Agriculture Peshawar Pakistan. ${ }^{5}$ Brady Urological Institute, Johns Hopkins University School of Medicine, Baltimore, MD 21287-2101, USA. ${ }^{6}$ Institute of Basic Medical Sciences, Khyber Medical University Peshawar Pakistan.

\section{Authors' contributions}

SA and SK designed and gave a critical view of manuscript writing. NU helped in collection of samples/data and SNK performed Lab analysis. IA and SS gave critical view of manuscript writing and participated in data analysis. All the authors' read and approved the final manuscript. SA, NH reviewed the final manuscript and made critical amendments in the data presentation. All authors read and approved the final manuscript.

Competing interests

The authors declare that they have no competing interests.

Received: 18 March 2011 Accepted: 6 June 2011 Published: 6 June 2011

\section{References}

1. Singhal V, Bora D, Singh S: Hepatitis B in health care workers: Indian scenario. Journal of Laboratory Physicians 2009, 1(2):41-48. 
2. Hussain S, Patrick NA, Shams R: Hepatitis B and C Prevalence and Prevention Awareness among Health Care Workers in a Tertiary Care Hospital. International Journal of Pathology 2010, 8(1):16-21.

3. Qureshi H, Bile KM, Jooma R, Alam SE, Afridi HUR: Prevalence of hepatitis $B$ and $C$ viral infections in Pakistan: findings of a national survey appealing for effective prevention and control measures. EMHJ 2010, 16.

4. Jahan S: Epidemiology of needlestick injuries among health care workers in a secondary care hospital in Saudi Arabia. Annals of Saudi medicine 2005, 25(3):233-8.

5. Sharma R, Rasania SK, Verma A, Saudan : Study of prevalence and response to needle stick injuries among health care workers in a tertiary care hospital in Delhi, India. Indian journal of community medicine 2010, 35(1):74-77.

6. Reis RK, Gir E, Canini SRMS: Accidents with biological material among undergraduate nursing students in a public Brazilian university. Braz J Infect 2004, 8(1):..

7. Ciorlia LAS, Zanetta DMT: Hepatitis B in healthcare workers: prevalence, vaccination and relation to occupational factors. Brazilian Journal of Infectious Diseases 2005, 9(5):384-389.

8. Aziz S, Memon A, Tily HI, Rasheed K, Jehangir K, Qureshi MS: HIV, Hepatitis $\mathrm{B}$ and $\mathrm{C}$ amongst health workers of Civil Hospital Karachi. J Pak Med Assoc 2002, 52(3):92-4.

9. Sarwar J, Gul N, Idris M, Rehman A-u, Farid J, Adeel MY: Seroprevalence of hepatitis B and hepatitis $C$ in health care workers in Abbott bad. J Ayub Med Coll Abbott Abad 2008, 20(3):27-29.

10. Memon MS, Ansari S, Nizamani R, Khatri NN, Mirza MM, Jafri W: Hepatitis B Vaccination status in health care workers of two university hospitals. Journal of Liquate University medical and health science 2007, 48-51.

11. Naz S, Ahmad M, Asghar H: Prevalence of Hepatitis 'B' Among Hospital Personnel in Combined Military Hospital (CMH) Muzaffarabad. International journal of Agriculture \& Biology 2002, 4(2):227-30.

12. Akhtar T: HBV vaccination status in the high-risk laboratory workers in the three major hospitals of Peshawar, Pakistan. J Med Res 2003, 42(2).

13. Kondili LA, Ulqinaku D, Hajdini M, Basho M, Chionne P, Madonna E, Taliani G, Candido A, Dentico P, Bino S, and Rapicetta M: Hepatitis B Virus Infection in Health Care Workers in Albania: a Country still Highly Endemic for HBV Infection. Springer Link 2007, 35(2):94-97.

14. Chiarakul S, Eunumjitkul K, Vuttiopas S, Vorapimol RA, Kaewkungwal J, Poovorawan Y: Seroprevalence and Risk Factors of Hepatitis B Virus Infection among Health Care Workers at the Institute of Neurology. J Med Assoc Thai 2007, 90(8):1536-45.

15. Lachowicz R, Matthews SA: The pattern of sharps injury to health care workers at Witbank Hospital. Fam Pract 2009, 51(2):148-151.

16. Beltrami EM, Williams IT, Shapiro CN, Mary E: Risk and Management of Blood-Borne Infections in Health Care Workers. Clin Microbiol Rev 2000, 13(3):385-407.

17. Shrestha K, Bhattarai MD: Study of Hepatitis B among different categories of HCWs. J Coll Physicians Surg Pak 2006, 16(2):108-11.

18. Shin BM, Yoo HM, Lee SL, Park SK: Seroprevalence of Hepatitis B Virus among Health Care Workers in Korea. The Korean Academy of Medical Sciences 2006, 21(1):58-62.

19. Belo AC: Prevalence of Hepatitis B virus markers in surgeons in Lagos, Nigeria. East African Medical Jounal 2000, 77(5):283-285.

20. Rampal L, Zakaria R, Sook LW, Zain AM: Needle Stick and Sharps Injuries and Factors Associated Among Health Care Workers in a Malaysian Hospital. European Journal of Social Sciences 2010, 13(3):354-362.

21. Hadadi A, Afhami S, Karbakhsh M, Esmailpour N: Occupational exposure to body fluids among healthcare workers: a report From Iran. Singapore Med J 2008, 49(6):429.

22. Zafar A, Habib F, Hadwani R, Ejaz M, Khowaja K, Khowaja R, Irfan S: Impact of infection control activities on the rate of needle stick injuries at a tertiary care hospital of Pakistan over a period of six years: an observational study. BMC Infect Dis 2009, 9:78

23. Pilakasiri C, Gibbons RV, Jarman RG, Supyapoung S, Myint KS: Hepatitis antibody profile of Royal Thai Army nursing students. Trop Med Int Health 2009, 14:609-11.

24. Singh G, Singh MP, Walia I, Sarin C, Ratho RK: Screening for hepatitis B and $C$ viral markers among nursing students in a tertiary care hospital. Indian J of Medical Micrbiology 2010, 28(1):78-79.
25. Waheed Y, Bin-Rahat T, Safi SZ, Qadri I: Epidemiological patterns and risk factors associated with hepatitis B virus in Pakistani population. Asian Biomedicine 2010, 4(4):547-554.

26. Ali SA, Donahue RM, Qureshi H, Vermund SH: Hepatitis B and hepatitis C in Pakistan: prevalence and risk factors. Int J Infect Dis 2009, 13:9-19.

27. Haider MZ, Malik AM, Ahmad N, Javid M, Yasrab M: Screening for Hepatitis B and C. Professional Medical J 2006, 13(3):460-63.

28. Mengal H, Hwteerakul N, Suwannapong N, Rajatanun T: Factors Relating to Acceptance of Hepatitis B Virus Vaccination by Nursing Students in a Tertiary Hospital, Pakistan. J Health Popul Nutr 2008, 26(1):46-53.

29. Jadoon NA, Shehzad MA, Yaqoob R, Raza A, Hussain MI: Hepatitis B Vaccination status of Health care workers at a tertiary care hospital in Multan. Nishtar Medical Journal 2009, 1(1):23-27.

30. Khurram M, ljaz K, Bushra MT, Khan NY, Bushra H, Hussain W: Needlestick injuries: A survey of doctors working at tertiary care hospitals of Rawalpindi. PMA 2011, 61:63.

31. Amini-Ranjbar S, Motlagh ME: Hepatitis B Vaccination Coverage Among Iranian Medical Students and Nursing Staff. American Journal of Applied Sciences 2008, 5(6):747-749.

32. Vaswani AS, Shaikh NA, Bhatty SA, Ghuman F, Irfan M: Hepatitis B Vaccination status among Health care workers at civil hospital Karachi. Medical Channel 2010, 16(1):45-51.

33. Hussain S, Patrick NA, Shams R: Hepatitis B and C Prevalence and Prevention Awareness among Health Care Workers in a Tertiary Care Hospital. International Journal of Pathology 2010, 8(1):16-21.

34. Ahmed H, Rauf MA, Farooqi Jl, Khan N, Saad, Imtiaz, Ali N, Aysha, Aman, Jan K, Zubair , Fazal-e-Mola, Nawaz M, Ahmad F, Masood-ur-Rehman : Status and Attitude Towards hepatitis ' $B$ ' virus Vaccination in staff of lady reading hospital Peshawar. JPMI 2009, 23(3):209-212.

doi:10.1186/1743-422X-8-275

Cite this article as: Attaullah et al:: Prevalence of HBV and HBV vaccination coverage in health care workers of tertiary hospitals of Peshawar, Pakistan. Virology Journal 2011 8:275.

\section{Submit your next manuscript to BioMed Central and take full advantage of:}

- Convenient online submission

- Thorough peer review

- No space constraints or color figure charges

- Immediate publication on acceptance

- Inclusion in PubMed, CAS, Scopus and Google Scholar

- Research which is freely available for redistribution

Submit your manuscript at www.biomedcentral.com/submit
C Biomed Central 